$\$ 225,000$ and those who are below it," she says. "If you can only afford to hire two people, it's hard to be productive."

Berg stresses that the analysis is a conversation-starter, not a judgement to be applied mechanically. "If you just say, 'Based on your funding level, you should be publishing seven papers and you are only publishing four, and one of those four is the discovery of RNA interference, that clearly would be the wrong way to think about things," he says.

Raphael Kopan, a developmental biologist and NIGMS grantee who this year ran his lab at Washington University in St Louis on $\$ 800,000$, says that Berg should be applauded for trying to scientifically analyse what his institute gets

\section{DNATURE.COM}

Are measures of scientific productivity fair? Visit: go.nature.com/nj2xqk for its investment. But without segregating the data - comparing, for instance, investigatorinitiated grants with projects instigated by the NIGMS, or intramural with extramural investigators - "it may lead to the wrong conclusion - that scientists do best if their funds are limited and their labs are small. I don't think this is necessarily correct," says Kopan.

Still, Berg's analysis has served a purpose: validating a 20 -year-old NIGMS policy of generally denying new grants to well funded labs. Since 1999, that has meant labs with more than $\$ 750,000$ in direct support from all sources, including the award being applied for.

Marburger says that Berg's analysis provides a "reality check" of that policy. The results, he says, are "an indication that they aren't making a big mistake".
Berg's next project will be to tackle the impact of the abbreviated grant-application forms that came into effect at the NIH in January. Among other things, he will be asking whether and how the slimmed-down form for the agency's mainstay grants is affecting the scores that applicants receive.

Whatever happens, the future is likely to bring more austerity, making it important for defenders of science agencies to arm themselves with the best quantitative ammunition they can generate. In this environment, questions such as Berg's "are very good to ask", says Kopan, who argues that Congress is already effectively cutting the NIH by failing to keep its budget growing as quickly as the costs of doing biomedical research. If cuts have to be made, he says, "we might as well go ahead and do it correctly".

\title{
UK science will be judged on impact
}

\section{Pilot scheme paves way for university research to be awarded on the basis of society benefits.}

\section{BY NATASHA GILBERT}

$\mathrm{R}$ esearch funding agencies have long dreamed of favouring scientists who have a track record of turning their work into tangible benefits for society and the economy. Attempts to judge 'impact' have been controversial, but the UK government thinks it has hit on a workable scheme. Last week, the Higher Education Funding Council for England (HEFCE) unveiled the results of a year-long pilot study that showed that using peer-review panels to assess the impact of research in UK universities is "workable" and "robust".

The idea of getting tangible returns from research funding aligns with the current coalition government's demands that researchers "do more for less", in the words of business secretary Vince Cable. With the success of the pilot study, the method looks set to become a key part of the nation's research audit system by 2014 . This Research Excellence Framework (REF) will replace the Research Assessment Exercise (RAE), which did not factor research impact into its calculations, and will be used to apportion more than $£ 1.5$ billion (US $\$ 2.4$ billion) per year. Research impact is expected to contribute up to $25 \%$ to the overall rating of a university department's research quality.

In the pilot study, university departments submitted case studies describing the impact of the work done by one in ten of their researchers over the past 17 years. Other academics and industry scientists on subject-specific panels reviewed the case studies, and awarded rankings from $4^{*}$ (the best) to unclassified. Eleven
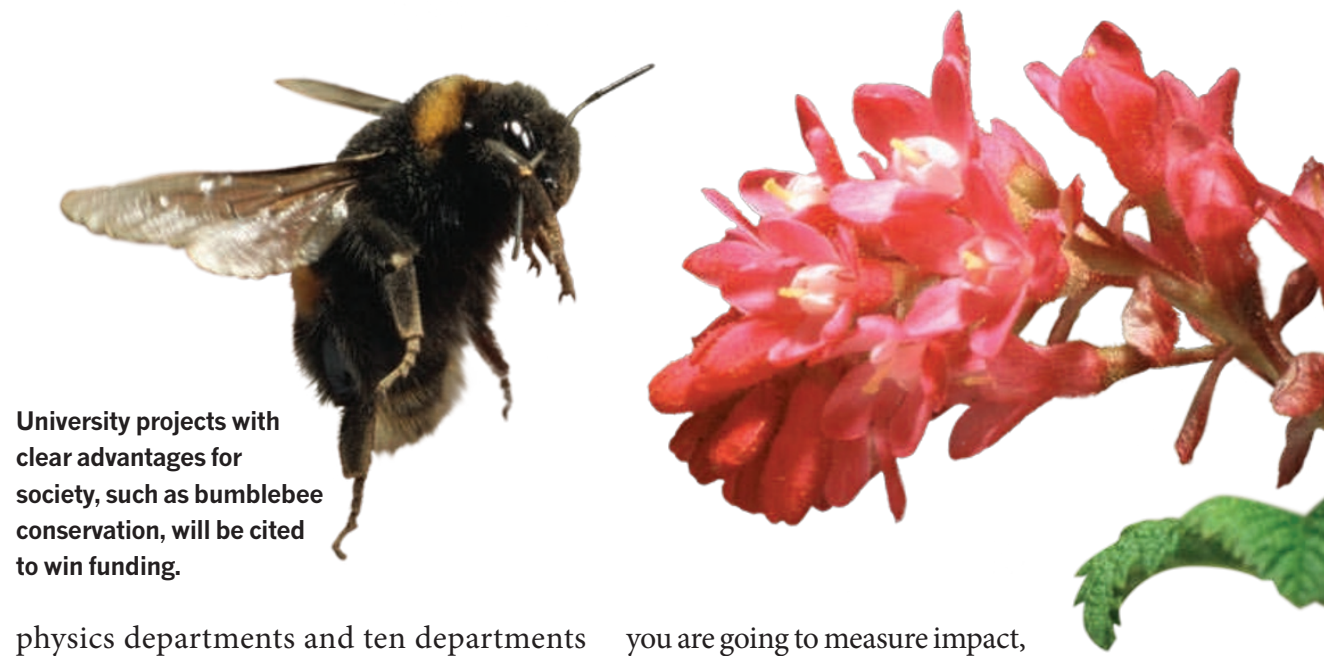

physics departments and ten departments of clinical medicine and of Earth systems and environmental science took part in the exercise. 'Impacts' included the establishment of spin-out companies, influence on policy relating to the environment, or the development of products such as computer software or technology.

Many academics are concerned that the added focus on research impact would skew funding towards applied research. Jonathan Grant, president of RAND Europe, a research consultancy based in Cambridge, UK, wrote a report last year criticizing the REF, and argues that impact should determine only $10-20 \%$ of universities' funding to avoid channelling

\section{$\rightarrow$ NATURE.COM}

For a longer version of this story, see: go.nature.com/qbkcgr funds away from blueskies research. However, the pilot's successful use of peer-review panels has convinced him that "if you are going to measure impact, this is the way to do it".

HEFCE will unveil a final plan for the REF in February 2011, but universities say there are still some problems to be ironed out. Anna Grey, research manager at the University of York, UK, says that some of her university's industry partners were not happy to release the details it needed to demonstrate impact, such as financial savings made as a result of products developed by the university. "Unless we can prove to the companies that the information will remain confidential, we will struggle to get hard evidence of impact," she says.

And Peter Main, director of education and science at the Institute of Physics in London, worries that universities could pressure departments to continue research in fields that have generated impact in the past, "even when more future impact might be generated from new directions". 